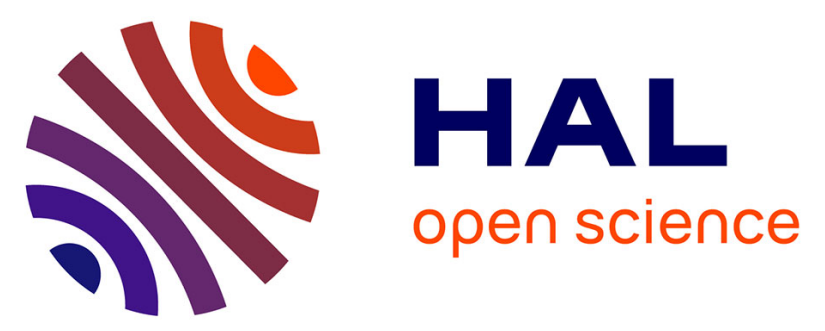

\title{
Isothermal vapor-liquid equilibrium data for the trifluoromethane (R23) + 2,3,3,3-tetrafluoroprop-1-ene (R1234yf) system at temperatures from 254 to $348 \mathrm{~K}$
} Hakim Madani, Alain Valtz, Fan Zhang, El Abbadi Jamal, Céline Houriez, Patrice Paricaud, Christophe Coquelet

\section{To cite this version:}

Hakim Madani, Alain Valtz, Fan Zhang, El Abbadi Jamal, Céline Houriez, et al.. Isothermal vaporliquid equilibrium data for the trifluoromethane (R23) + 2,3,3,3-tetrafluoroprop-1-ene (R1234yf) system at temperatures from 254 to 348 K. Fluid Phase Equilibria, 2016, 10.1016/j.fluid.2016.02.005 . hal-01305721

HAL Id: hal-01305721

https: / hal-mines-paristech.archives-ouvertes.fr/hal-01305721

Submitted on 21 Apr 2016

HAL is a multi-disciplinary open access archive for the deposit and dissemination of scientific research documents, whether they are published or not. The documents may come from teaching and research institutions in France or abroad, or from public or private research centers.
L'archive ouverte pluridisciplinaire HAL, est destinée au dépôt et à la diffusion de documents scientifiques de niveau recherche, publiés ou non, émanant des établissements d'enseignement et de recherche français ou étrangers, des laboratoires publics ou privés. 
Isothermal vapor-liquid equilibrium data for the trifluoromethane $(\mathbf{R} 23)+\mathbf{2 , 3 , 3 , 3 -}$ tetrafluoroprop-1-ene (R1234yf) system at temperatures from 254 to $348 \mathrm{~K}$

Hakim Madani $^{\mathrm{a}, *}$, Alain Valtz ${ }^{\mathrm{b}}$, Fan Zhang ${ }^{\mathrm{b}}$, Jamal El Abbadi ${ }^{\mathrm{b}}$, Céline Houriez ${ }^{\mathrm{b}}$, Patrice Paricaud $^{\mathrm{c}, \mathrm{b}}$, Christophe Coquelet ${ }^{\mathrm{b},}$,

(a) Laboratoire d'Étude des Systèmes Énergétiques Industriels, Département de Mécanique, Faculté de Technologie, Université de Batna, Algérie.

(b) MINES ParisTech, PSL Research University, CTP-Centre of Thermodynamics of Processes, 35 rue Saint-Honoré, 77300 Fontainebleau, France.

${ }^{(c)}$ UCP, ENSTA ParisTech, Université Paris-Saclay, 828 boulevard des Maréchaux, 91762 Palaiseau Cedex, France. Abstract

In this study, we present new experimental data of vapor-liquid equilibrium for the binary system trifluoromethane $(\mathrm{R} 23)+$ 2,3,3,3-tetrafluoropropene (R1234yf), measured at $254.10,273.43,293.24,303.17,318.08,332.97$, and $348.40 \mathrm{~K}$ and at pressure ranging from 0.1568 to $4.3553 \mathrm{MPa}$. A "static-analytic"-type apparatus is used to do the measurements, with sampling of the equilibrium phases via capillary sampler $\left(\mathrm{ROLSI}^{\mathrm{TM}}\right)$. We used two different methods to model the obtained isothermal P-x-y data: 1) the Peng-Robinson cubic equation of state, incorporating the Mathias-Copeman alpha function, combined with the NRTL excess free energy model and Wong-Sandler mixing rules, and 2) the PC-SAFT equation of state. Both models show a very good agreement with the experimental data.

Keywords: VLE data, R23, R1234yf, critical point, PC-SAFT, EoS.

*Corresponding Author: madani_hakim@yahoo.fr

Tel: 00213556027708 


\section{Introduction}

Due to the Montréal and Kyoto protocols, and to directives of the European Parliament and of the Council of the European Union, member states of the European Community have to use working fluids with low Ozone Depletion Potential (ODP) and low Global Warming Potential (GWP) to reduce emissions from different systems such as, for instance, air conditioning, refrigeration, and heat pump engines. For example, based on the directive 2006/40/EC, member states of the European Community are invited to use, from 1 January 2011, fluids for air-conditioning vehicles with a GWP value lower than 150. Consequently, because of its 100-year GWP of 1430, the 1,1,1,2tetrafluoroethane (HFC134a), which was the most used refrigerant for vehicle airconditioning systems has to be replaced by more environmentally benign refrigerants [1].

Recently, a next-generation refrigerant, the 2,3,3,3-tetrafluoropropo-1-ene (R1234yf), has been proposed as a very promising alternative solution in automobile airconditioning systems: it has a very low 100-year GWP (4) [2] and its thermodynamic properties make it a good candidate to best replace R134a [3]. The only drawback of R1234yf is a weak flammability (ASHRAE class A2L).

Additionally, relative to R134a, R1234yf has smaller latent heat of vaporisation which leads to larger mass flow rates, larger pressure drops in heat exchangers and connection pipes, and ultimately, lower coefficients of performance [1].

To explore the performance of R1234yf in technical applications, measurements of its thermophysical properties, and particularly the thermodynamic ones, are necessary. Therefore, as the use of R1234yf is often discussed as component of refrigerant blends, the knowledge of thermodynamic properties of binary systems involving R1234yf are 
very important. In the literature, this type of data are very scarce, however, we can cite for instance the study of Kamika and co-workers [4] for binary mixtures of R1234yf with R32, R125, and R134a, and the study of Juntarachat and co-workers [5] concerning the system $\mathrm{CO}_{2}+\mathrm{R} 1234 \mathrm{yf}$. The current paper presents new vapor-liquid equilibrium (VLE) data for the R23 + R1234yf binary system at seven temperatures (254.10, 273.43, 293.24, 303.17, 318.08, 332.97, and 348.40 K). Three isotherms are below the critical temperature of R23 and four are above it.

Two different thermodynamic methods are used to model the system. The first one is based on the Peng-Robinson (PR) cubic equation of state (EoS) [6] using the MathiasCopeman alpha function [7], combined with the Non Random Two Liquids (NRTL) activity coefficient model [9] and the Wong-Sandler (WS) mixing rules [8]. The second model is the Perturbed-Chain Statistical Associating Fluid Theory (PC-SAFT) EoS, developed by Gross and Sadowski [10]. Neither polar nor association contributions are considered for the PC-SAFT model.

\section{Experimental Section}

\subsection{Materials}

All pure compounds were obtained commercially and used without any additional purification. The purities and the suppliers of the compounds are listed in Table (1).

\subsection{Apparatus}

The apparatus (from CTP research group) used in this work is based on a "staticanalytic" method with liquid and vapor phase sampling. This apparatus is similar to the equipments used in previous studies [11, 12, 13, and 14].

The equilibrium cell is immersed inside a temperature regulated liquid bath. Temperatures are measured with two platinum resistance thermometer probes (Pt100) inserted inside walls of the equilibrium cell. These Pt100 probes are calibrated against a 
$25 \Omega$ reference probe (TINSLEY Precision Instrument) certified by the Laboratoire National d'Essais (Paris) following the International Temperature Scale 1990 protocol.

Pressures are measured using a pressure transducer (Druck, type PTX611, range: 0 - $100 \mathrm{MPa}$ ). This sensor is calibrated against a dead weight pressure balance (5202S model from Desgranges \& Huot).

Temperature and pressure data acquisition is performed with a computer linked to an HP unit (HP34970A). The resulting uncertainties in this work are $u(T, k=2)=U(T)=$ $0.04 \mathrm{~K}$ and $\mathrm{u}(\mathrm{P}, \mathrm{k}=2)=\mathrm{U}(\mathrm{P})=0.0004 \mathrm{MPa}$.

The analytical work was carried out using a gas chromatograph equipped with a thermal conductivity detector (TCD) connected to a data acquisition system.

The analytical column used for the separation was a 1\% RT 1000 on CarboBlack B model with 60/80 mesh (2 mm internal diameter, Silcostell tube, $2.4 \mathrm{~m}$ length) from RESTEK. The TCD was repeatedly calibrated by introducing known amounts of each pure compound through a syringe in the injector of the gas chromatograph. Taking into account the uncertainties due to calibrations and dispersions of analyses, resulting uncertainties on vapor and liquid mole fractions are estimated to be less than $\mathrm{u}(z$, $k=2)=\mathrm{U}(\mathrm{z})=0.004$.

\subsection{Experimental Procedure}

At room temperature, the equilibrium cell and its loading lines are evacuated down to 0.1 Pa. The cell is first loaded with R1234yf as liquid (about $5 \mathrm{~cm}^{3}$ ). Equilibrium temperature is assumed to be reached when the two Pt100 probes (one located at top of equilibrium cell, the other in the bottom) give equivalent temperature values within the experimental uncertainty for at least 10 minutes. The vapor pressure of the R1234yf (the heavier component) is first recorded at equilibrium temperature. Then R23 (the lighter component) is introduced step by step, leading to successive equilibrium mixtures of 
increasing overall R23 content. After each new R23 loading, equilibrium is assumed when the total pressure remains unchanged within $\pm 1.0 \mathrm{kPa}$ during a period of 10 minutes under efficient stirring. For each equilibrium condition, at least five samples of both vapor and liquid phases are withdrawn using the $\mathrm{ROLSI}^{\mathrm{TM}}$ capillary pneumatic samplers [15] and analyzed in order to check for measurements repeatability.

\section{Thermodynamic modeling}

\subsection{Peng-Robinson Equation of State}

The system was modeled by means of an in-house software. For the pure compounds, we used the PR EoS [6], with the Mathias-Copeman [7] alpha function (Eq. 1 and 2) for accurate representation of the vapor pressures

$\alpha(T)=\left[1+c_{1}\left(1-\sqrt{\frac{T}{T_{C}}}\right)+c_{2}\left(1-\sqrt{\frac{T}{T_{C}}}\right)^{2}+c_{3}\left(1-\sqrt{\frac{T}{T_{C}}}\right)^{3}\right]^{2}$

If $\mathrm{T}>\mathrm{T}_{\mathrm{C}}$,

$\alpha(T)=\left[1+c_{1}\left(1-\sqrt{\frac{T}{T_{C}}}\right)\right]^{2}$

$c_{1}, c_{2}$, and $c_{3}$ are the three adjustable parameters of the Mathias-Copeman equation and $T_{\mathrm{C}}$ is the critical temperature. The critical temperatures and critical pressures $\left(P_{\mathrm{C}}\right)$ for each of the two pure components are provided in Table (2).

We applied the PR EoS to the mixture by using the Wong-Sandler mixing rules for both vapor and liquid phases, defined by [8]: 


$$
b=\frac{\sum_{i} \sum_{j} z_{i} z_{j}\left(b_{i j}-\frac{a_{i j}}{R T}\right)}{1-\left(\frac{\sum_{i} z_{i} \frac{a_{i}}{b_{i}}}{R T}+\frac{g^{E}\left(T, P=\infty, z_{i}\right)}{C R T}\right)}
$$

and

$$
b-\frac{a}{R T}=\sum_{i} \sum_{j} z_{i} z_{j}\left(b_{i j}-\frac{a_{i j}}{R T}\right)
$$

with

$b_{i j}-\frac{a_{i j}}{R T}=\frac{1}{2}\left[\left(b_{i}-\frac{a_{i}}{R T}\right)+\left(b_{j}-\frac{a_{j}}{R T}\right)\right]\left(1-k_{i j}\right)$

$z_{i}$ is the mole fraction (vapor or liquid). $k_{i j}$ is an adjustable binary interaction parameter and $\mathrm{C}$ is a constant equal to 0.62323 . The model chosen for the excess Gibbs energy $\left(g^{E}\right)$ is the NRTL [9] local composition model:

$$
\frac{g^{E}\left(T, P, z_{i}\right)}{R T}=\sum_{i} z_{i} \sum_{j} \frac{z_{j} \exp \left(-\alpha_{j i} \tau_{j i}\right)}{\sum_{k} z_{k} \exp \left(-\alpha_{k i} \tau_{k i}\right)} \tau_{j i}
$$

where $\alpha_{i j}$ and $\tau_{i j}$ are the adjustable parameters of the NRTL model, with $\tau_{i i}=0$ and $\alpha_{i i}=0$. It is recommended to use a value of $\alpha_{12}$ equal to 0.3 for systems involving a polar compound [9]. $\tau_{12}$ and $\tau_{21}$ are adjusted directly to VLE data through a modified simplex algorithm [16], using the following objective function (flash algorithm):

$$
F=\frac{100}{N}\left[\sum_{1}^{N}\left(\frac{x_{\exp }-x_{c a l}}{x_{\exp }}\right)^{2}+\sum_{1}^{N}\left(\frac{y_{\exp }-y_{c a l}}{y_{\exp }}\right)^{2}\right]
$$


where $N$ is the number of data points, $x_{\text {exp }}$ and $x_{c a l}$ the measured and calculated liquid phase mole fractions, and $y_{\text {exp }}$ and $y_{c a l}$ the measured and calculated vapor phase mole fractions, respectively.

\subsection{PC SAFT model}

The system was also modeled by means of the PC-SAFT EoS. In this model, molecules are considered as chains of spherical segments, and the hard-chain fluid is taken as the reference system in the perturbation theory. The Helmholtz free energy is expressed as a sum of different contributions as:

$$
A=A^{\text {ideal }}+\left(A^{\text {hs }}+A^{\text {chain }}+A^{\text {disp }}\right)
$$

where $A^{\text {ideal }}$ is the Helmholtz free energy of an ideal gas mixture, $A^{\text {hs }}$ the contribution of the hard spherical segments, $\mathrm{A}^{\text {chain }}$ the chain contribution, and $\mathrm{A}^{\mathrm{disp}}$ the dispersion contribution interactions. The reader is directed to have a look in the PC-SAFT original paper [10] for further details. Here, no polar contribution has been considered, and the R23 and R1234yf refrigerants are modeled as non-associating molecules for the sake of simplicity.

\subsection{Modeling of the pure compounds R23 and R1234yf}

The pure compound PC-SAFT parameters (the below-defined $\mathrm{m}, \sigma$, and $\varepsilon / \mathrm{k}$ parameters), have been adjusted on VLE data generated with the REFPROP 9.0 software [17], by considering the following objective function:

$$
F_{o b j}=\frac{100}{N}\left[\sum_{1}^{N}\left(\frac{p_{\exp }-P_{c a l}}{p_{\exp }}\right)^{2}+\sum_{1}^{N}\left(\frac{\rho_{\exp }^{L}-\rho_{c a I}^{L}}{\rho_{\exp }^{L}}\right)^{2}\right],
$$

Where $\mathrm{N}$ is the number of data points, $\mathrm{P}_{\text {exp }}$ is the experimental vapor pressure, $\mathrm{P}_{\text {cal }}$ the calculated vapor pressure, $\rho^{\mathrm{L}}$ exp the experimental saturated liquid density and $\rho^{\mathrm{L}}$ cal is the calculated saturated liquid density. 
The parameters $m, \sigma$, and $\varepsilon$ of the PC-SAFT EoS, are the number of segments, the segment diameter, and the potential well depth, respectively. $\mathrm{k}$ is the Boltzmann constant. The calculated vapor pressures and saturated liquid and vapor densities for R23 and R1234yf are compared to the data generated with the REFPROP 9.0 software [17] in Figures (4) and (5).

\section{Results and discussion:}

The average absolute deviation, AAD, and the BIAS (see table (5)), applied on liquid and vapor phase mole fractions, are defined by:

$$
\begin{aligned}
& A A D=(100 / N) \sum\left|\left(U_{c a l}-U_{\exp }\right) / U_{\exp }\right| \\
& B I A S=(100 / N) \sum\left(\left(U_{\text {exp }}-U_{c a l}\right) / U_{\text {exp }}\right)
\end{aligned}
$$

where $\mathrm{N}$ is the number of data points, and $\mathrm{U}$ is $\mathrm{P}, \mathrm{x}_{1}$ or $\mathrm{y}_{1}$.

\subsection{Vapor pressures data}

R23 and R1234yf vapor pressures were calculated from REFPROP 9.0 (see figure 4) and used to adjust Mathias-Copeman alpha function parameters (see table 2). The deviations are $0.01 \%$ and $0.03 \%$ for R1334yf and R23 respectively.

4.2 Vapor-liquid equilibrium data for the R23 + R1234yf mixture

\subsubsection{Peng- Robinson EoS:}

The experimental and calculated VLE data are reported in Table (3) and plotted on Figure (1). The adjusted parameters are given in Table (4) and plotted on figures (2) and (3).

\subsubsection{PC SAFT EoS}

The optimized parameters are reported in Table 6 . The average absolute deviation AAD and the BIAS have been also calculated for the vapor pressures and saturated liquid 
densities of the two pure compounds and presented in Table 7). The relative deviation (RD) for pure compounds R23 and R1234yf with PC-SAFT model is shown in figure (6).

The vapor pressure and the saturated liquid and vapor densities of the two pure components are in overall well represented by PC-SAFT EoS far from the critical points. The deviations for the vapor density are a slightly higher than the deviations for the other two properties.

For both pure compounds, we can notice that the description of saturated liquid and vapor densities is not good near the critical points. In this region, the deviations for densities can reach values higher than $40 \%$. This could be explained by the fact that we do not use a polar term in the PC-SAFT model.

In the PC-SAFT EoS, the binary interaction parameter $k_{i j}$ is introduced to correct the segment-segment interactions of unlike chains, according to the conventional LorentzBerthelot combining rule [10]:

$$
\varepsilon_{i j}=\sqrt{\varepsilon_{i} \varepsilon_{j}}\left(1-k_{i j}\right)
$$

The binary interaction parameter $k_{i j}$ has been adjusted on the experimental data, by using the flash type calculation and the objective function given in equation (7).

A different value of binary interaction parameter $k_{i j}$ is used for each isotherm to observe a trend with respect to the temperature of the system (Figure 7). All the adjusted $k_{i j}$ values and deviations are reported in Table (8).

From Figure (7), we can notice two different trends of the binary interaction parameter $\mathrm{k}_{\mathrm{ij}}$ with respect to the temperature, depending on whether we are below or over the critical temperature of R23 $\left(\mathrm{T}_{\mathrm{c}}=299.29 \mathrm{~K}\right)$. In fact, we have a discontinuity of the function $k_{i j}(T)$ at the critical temperature of R23. 
The calculated values for the liquid mole fraction $\mathrm{x}_{1}$ and the vapor mole fraction $\mathrm{y}_{1}$ can be found in Table (3).

From Figure (8), we can see that the representation of the data by the PC-SAFT model is good for the temperatures below the critical point of R23, but the PC-SAFT model overestimates the vapor-liquid critical pressure and composition of the mixture at high temperatures from $303.17 \mathrm{~K}$. This can be explained by the fact that the PC-SAFT model overestimates the critical pressure of pure R23.

We calculated the AAD and the BIAS for the liquid and vapor phase compositions, which are reported in Table (8).

We can notice that the modeling of the data with PC-SAFT is less accurate than that obtained with the PR EoS + Mathias-Copeman alpha function, combined with the Wong-Sandler mixing rules + NRTL. This can be explained by the fact that we do not consider the polar contribution to the Helmholtz free energy in the PC-SAFT EoS, which could be important for better reproducing the vapor pressures and the coexistence densities, as well as the critical point.

\subsection{Critical lines computation}

The isothermal experimental data have been used to estimate the critical point (composition and pressure). The critical loci for binary mixtures and the near-critical behavior were approximated by the use of extended scaling laws, as described previously by Ungerer et al. [19] and used in previous work [14]. In this method, the near-critical part of the pressure-composition diagram was represented by complementing the nearcritical scaling law with a linear term, as follows:

$y-x=\lambda_{1}\left(P_{C}-P\right)+\mu\left(P_{C}-P\right)^{\beta}$

And the following relation is used for the mid-composition: 
$\frac{y+x}{2}-x_{C}=\lambda_{2}\left(P_{C}-P\right)$

Parameters $\lambda_{1}, \lambda_{2}, \mu, P_{c}$ and $x_{c}$ are adjusted using experimental data close to the mixture critical point. The values are reported in tables (9) and (10) and plotted on figure (9).

To calculate the critical line using the PR EoS with WS mixing rules involving the NRTL model, we used the method of Heidemann and Khalil [20] adapted by Stockfleth and Dohrn [21], who proposed a generalized algorithm to calculate the critical points by using any type of EoS and mixing-rule. The temperature dependent binary parameters are those obtained by fitting VLE data in the R23 supercritical domain. Results are plotted on Figures (3) and (9). We have obtained a predicted critical locus line in good agreement with the isothermal phase envelopes.

\section{Conclusion:}

In this paper, VLE data at seven temperatures for the R23 + R1234yf system are presented. They were obtained using an experimental technique based on a "staticanalytic" method. Two different methods were used to model the data: the PR EoS, with the Mathias-Copeman alpha function and the Wong-Sandler mixing rules involving the NRTL model, and the PC-SAFT EoS without polar and association contributions. It was found that the two models give results in very good agreement with experiment. Moreover, it was found that the PC-SAFT model is not able to represent the VLE data in the critical region. 


\section{List of symbols:}

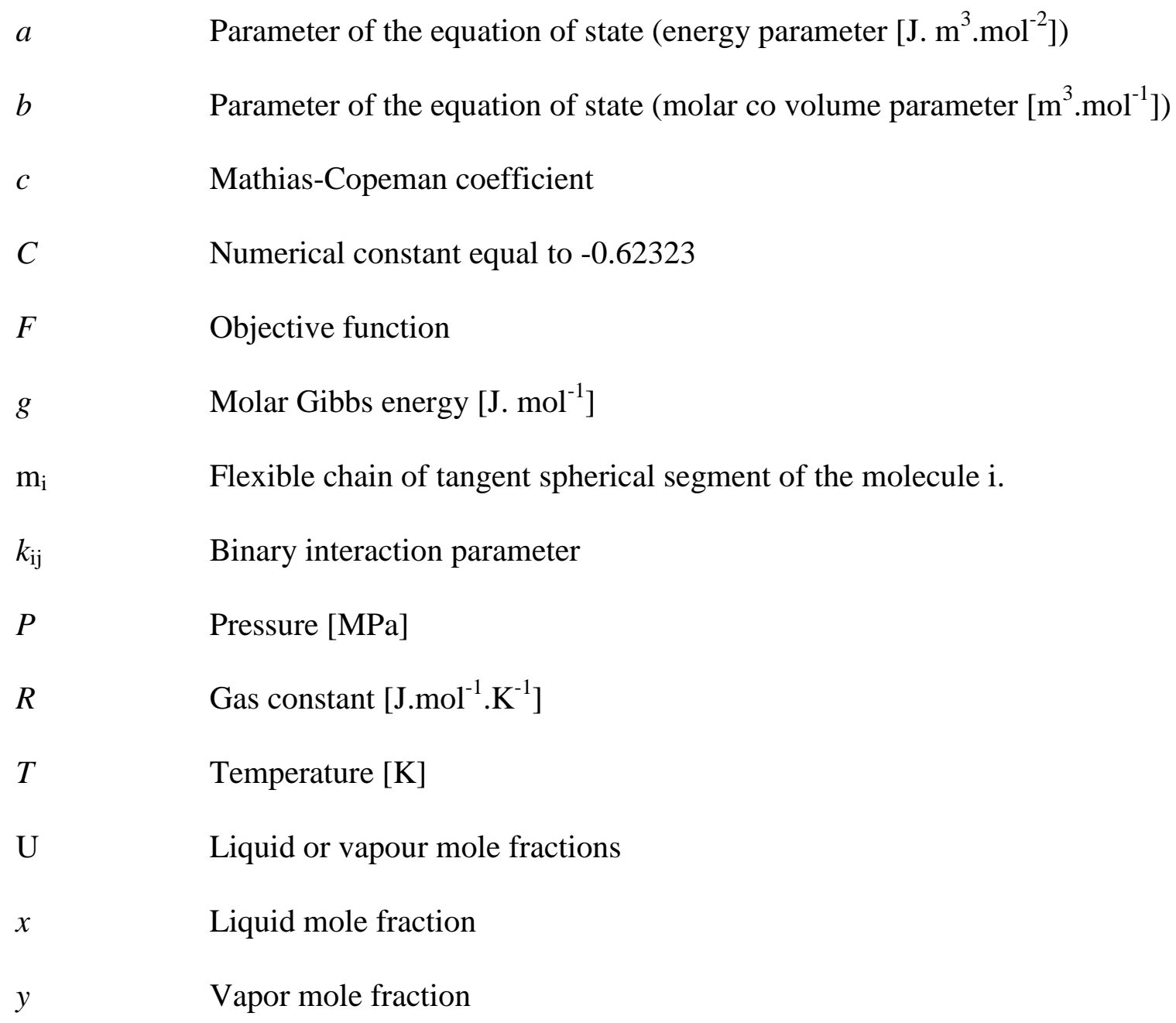

\section{Greek letters:}

$\begin{array}{ll}\alpha_{i j} & \text { non randomness NRTL model parameter (Eq 6) } \\ \tau_{i j} & \text { NRTL model binary interaction parameter (Eq 6), } \\ \beta & \text { constant used in the Eq. (13) } \\ \varepsilon_{\mathrm{AB}} & \text { Association parameter Eq. (12) } \\ \lambda_{\mathrm{i}} & \text { parameters used in the Eqs. (13) and (14) } \\ \rho & \text { Density } \\ \sigma_{\mathrm{ij}} & \text { Diameter }\end{array}$




\section{Superscript}

$\begin{array}{ll}\text { Chain } & \text { Chain contribution interaction } \\ \text { Disp } & \text { Dispersion contribution interaction } \\ \text { hc } & \text { Hard chain } \\ \text { hs } & \text { Hard sphere } \\ E & \text { Excess property } \\ O & \text { Initial state }\end{array}$

\section{Subscripts}

C

Critical property

cal

Calculated property

$\exp$

Experimental property

$i, j$

Molecular species

1

R23

2

R1234yf

\section{Abbreviation}

GWP Global Warming Potential

PC-SAFT Perturbed-Chain Statistical Association Fluid Theory

PR EoS Peng-Robinson Equation of State

VLE Vapour-Liquid Equilibrium 


\section{References :}

[1] S. Bobbo, C. Zilio, M. Scattolin, L. Fedele, International Journal of Refrigeration, 40 (2014) $302-308$.

[2] O.J. Nielson, M.S. Javadi, M.P. Sulback Andersen, M.D. Hurley, T.J. Wallington, R. Singh, Chem.Phys.Left 439 (2007) 18-22.

[3] SAE, 2009. Retrieved online at: http://www.sae.org/Standardsdev/tsb/cooperative/crp 1234-3.pdf

[4] T. Kamika, C. Dang, E. Hihara, International Journal of Refrigeration 36 (2013) 965 $-971$.

[5] N. Juntarachat, A. Valtz, C. Coquelet, R. Privat, J.N. Jaubert, International Journal of Refrigeration 47 (2014) 141 - 152.

[6] D.Y. Peng, D.B. Robinson, Ind. Eng. Chem. Fundam. 15 (1976) 59-64.

[7] P. M. Mathias, T. W. Copeman, Fluid Phase Equilib. 13 (1983) 91-108.

[8] D. S. H. Wong, S.I. Sandler, AIChE J. 38 (1992) 671-680.

[9] H. Renon, J. M. Prausnitz, AIChE J. 14 (1968) 135-144.

[10] J. Gross and G. Sadowski, In. Eng. Chem. Res., 40 (2001) 1244-1260.

[11] H. Madani, A. Valtz, C. Coquelet, A. H. Meniai, D. Richon, Fluid Phase Equilib., 268 (2008) $68-73$.

[12] H. Madani, A. Valtz, C. Coquelet, A. H. Meniai, D. Richon, The journal of Chemical Thermodynamics, 40 (2008) 1490 - 1494.

[13] H. Madani, A. Valtz, C. Coquelet, A. H. Meniai, D. Richon, International Journal of Refrigeration, 32 (2009) 1396 - 1402.

[14] H. Madani, A. Valtz, C. Coquelet, Fluid Phase Equilib. 354 (2013) 109 - 113.

[15] S. Laugier, D. Richon, Rev. Sci. Instrum. 57 (1986) 135 - 144.

[16] E. R. Åberg, A. G. Gustavsson, Analytica Chimica Acta 144 (1982) 39-53.

[17] E. W. Lemmon, L. Huber, M. O. McLinden, REFPROP, 2010.

[18] Dortmund Data Bank (DDB) version 2009, DDBST Software and Separation Technology GmbH, Oldenburg. Germany.

[19] P. Ungerer, B. Tavitian, A. Boutin, Application of Molecular Simulation in The Oil and Gaz Industry - Monte Carlo Methods, Edition Technip, Paris, 2005.

[20] R. A. Heidemann, A. M. Khalil, AIChE J. 26 (1980) 769 - 779.

[21] R. Stockfleth, R. Dohrn, Fluid Phase Equilib. 145 (1998) 43-52. 
Table 1: Purity and supplier of the chemical compounds used in this work.

\begin{tabular}{lll}
\hline Compound & Purity & Supplier \\
\hline R1234yf [CAS: 754-12-1] & $\geq 99$ vol\% & Honeywell \\
R23 [CAS: 75-46-7] & 99.5 wt.\% & Climalife \\
\hline
\end{tabular}


Table 2: Critical data and Mathias-Copeman coefficients for the pure compounds.

\begin{tabular}{cccccc}
\hline Compound & $T_{d} / \mathrm{K}$ & $P_{c} / \mathrm{MPa}$ & $c_{1}$ & $c_{2}$ & $c_{3}$ \\
\hline R23 & $299.29^{\mathrm{a}}$ & $4.8320^{\mathrm{a}}$ & 0.7490 & 0.0112 & 0.1269 \\
R1234yf & $367.85^{\mathrm{a}}$ & $3.3822^{\mathrm{a}}$ & 0.8103 & -0.4225 & 1.3265 \\
\hline
\end{tabular}

a : from [18] 
Table 3: Experimental and calculated VLE data with PR and PC-SAFT EoSs for the R23 (1) $-\mathrm{R} 1234 \mathrm{yf}(2)$ system and their standard uncertainties $(\mathrm{u})$ : $\mathrm{U}(\mathrm{T})=0.04 \mathrm{~K}, \mathrm{U}(\mathrm{P})=$ $0.0004 \mathrm{MPa}, \mathrm{U}(\mathrm{x}, \mathrm{y})=0.004$.

\begin{tabular}{|c|c|c|c|c|c|c|}
\hline \multicolumn{3}{|c|}{ Experimental data } & \multicolumn{2}{|c|}{ PR EOS } & \multicolumn{2}{|c|}{ PC-SAFT EOS } \\
\hline $\mathrm{P} / \mathrm{MPa}$ & $\mathrm{X}_{1 \mathrm{EXP}}$ & $\mathrm{y}_{1 \mathrm{EXP}}$ & $\mathrm{X}_{1 \mathrm{CAL}}$ & $\mathrm{y}_{1 \mathrm{CAL}}$ & $\mathrm{X}_{1 \mathrm{CAL}}$ & $\mathrm{y}_{1 \mathrm{CAL}}$ \\
\hline \multicolumn{7}{|c|}{$254.10 \mathrm{~K}$} \\
\hline 0.1568 & 0.000 & 0.000 & 0.000 & 0.000 & 0.000 & 0.000 \\
\hline 0.3505 & 0.147 & 0.583 & 0.150 & 0.590 & 0.153 & 0.595 \\
\hline 0.5088 & 0.280 & 0.742 & 0.277 & 0.744 & 0.277 & 0.749 \\
\hline 0.6679 & 0.411 & 0.828 & 0.408 & 0.828 & 0.403 & 0.832 \\
\hline 0.8219 & 0.538 & 0.882 & 0.535 & 0.881 & 0.525 & 0.884 \\
\hline 0.9926 & 0.676 & 0.925 & 0.674 & 0.924 & 0.659 & 0.925 \\
\hline 1.1378 & 0.787 & 0.952 & 0.787 & 0.952 & 0.771 & 0.952 \\
\hline 1.3162 & 0.913 & 0.981 & 0.918 & 0.982 & 0.903 & 0.980 \\
\hline \multicolumn{7}{|c|}{$273.43 \mathrm{~K}$} \\
\hline 0.3182 & 0.000 & 0.000 & 0.000 & 0.000 & 0.000 & 0.000 \\
\hline 0.5176 & 0.096 & 0.398 & 0.096 & 0.406 & 0.098 & 0.409 \\
\hline 0.8062 & 0.242 & 0.645 & 0.240 & 0.647 & 0.241 & 0.653 \\
\hline 1.0695 & 0.372 & 0.756 & 0.372 & 0.758 & 0.368 & 0.764 \\
\hline 1.3543 & 0.515 & 0.835 & 0.514 & 0.834 & 0.502 & 0.839 \\
\hline 1.6557 & 0.657 & 0.891 & 0.657 & 0.891 & 0.640 & 0.894 \\
\hline 1.9365 & 0.781 & 0.932 & 0.781 & 0.932 & 0.764 & 0.933 \\
\hline 2.2482 & 0.904 & 0.971 & 0.905 & 0.971 & 0.891 & 0.969 \\
\hline \multicolumn{7}{|c|}{$293.24 \mathrm{~K}$} \\
\hline 0.5927 & 0.000 & 0.000 & 0.000 & 0.000 & 0.000 & 0.000 \\
\hline 0.8863 & 0.091 & 0.323 & 0.093 & 0.341 & 0.095 & 0.342 \\
\hline 1.1871 & 0.195 & 0.521 & 0.193 & 0.523 & 0.193 & 0.527 \\
\hline 1.5799 & 0.323 & 0.664 & 0.324 & 0.663 & 0.317 & 0.667 \\
\hline 2.1023 & 0.493 & 0.778 & 0.491 & 0.775 & 0.476 & 0.778 \\
\hline 2.5401 & 0.623 & 0.838 & 0.622 & 0.839 & 0.604 & 0.841 \\
\hline 3.1171 & 0.779 & 0.904 & 0.779 & 0.904 & 0.760 & 0.904 \\
\hline 3.4994 & 0.869 & 0.939 & 0.871 & 0.940 & 0.854 & 0.939 \\
\hline \multicolumn{7}{|c|}{$303.17 \mathrm{~K}$} \\
\hline 0.7839 & 0.000 & 0.000 & 0.000 & 0.000 & 0.000 & 0.000 \\
\hline 1.2044 & 0.119 & 0.350 & 0.117 & 0.360 & 0.120 & 0.360 \\
\hline 1.6991 & 0.259 & 0.560 & 0.253 & 0.565 & 0.258 & 0.570 \\
\hline 2.0776 & 0.364 & 0.659 & 0.353 & 0.660 & 0.368 & 0.666 \\
\hline 2.4300 & 0.451 & 0.716 & 0.444 & 0.724 & 0.447 & 0.731 \\
\hline 2.9027 & 0.567 & 0.786 & 0.560 & 0.789 & 0.562 & 0.796 \\
\hline 3.2042 & 0.636 & 0.823 & 0.631 & 0.822 & 0.630 & 0.830 \\
\hline 3.5801 & 0.720 & 0.857 & 0.716 & 0.858 & 0.712 & 0.866 \\
\hline 3.9326 & 0.791 & 0.888 & 0.791 & 0.888 & 0.783 & 0.896 \\
\hline
\end{tabular}




\begin{tabular}{|c|c|c|c|c|c|c|}
\hline 4.1913 & 0.841 & 0.909 & 0.843 & 0.909 & 0.831 & 0.917 \\
\hline 4.4446 & 0.885 & 0.928 & 0.890 & 0.929 & 0.876 & 0.936 \\
\hline 4.6558 & 0.919 & 0.943 & 0.926 & 0.946 & 0.911 & 0.952 \\
\hline 4.8158 & 0.943 & 0.954 & 0.948 & 0.948 & 0.936 & 0.964 \\
\hline \multicolumn{7}{|c|}{$318.08 \mathrm{~K}$} \\
\hline 1.1534 & 0.000 & 0.000 & 0.000 & 0.000 & 0.000 & 0.000 \\
\hline 1.4283 & 0.062 & 0.183 & 0.063 & 0.191 & 0.062 & 0.186 \\
\hline 1.9633 & 0.183 & 0.411 & 0.181 & 0.415 & 0.183 & 0.419 \\
\hline 2.406 & 0.281 & 0.527 & 0.276 & 0.529 & 0.279 & 0.537 \\
\hline 2.9193 & 0.391 & 0.619 & 0.382 & 0.621 & 0.384 & 0.632 \\
\hline 3.3879 & 0.483 & 0.683 & 0.477 & 0.682 & 0.475 & 0.696 \\
\hline 3.8458 & 0.571 & 0.729 & 0.566 & 0.729 & 0.560 & 0.745 \\
\hline 4.4055 & 0.671 & 0.774 & 0.671 & 0.774 & 0.656 & 0.794 \\
\hline 4.6988 & 0.720 & 0.789 & 0.726 & 0.792 & 0.704 & 0.816 \\
\hline 4.8757 & 0.754 & 0.795 & 0.760 & 0.799 & 0.731 & 0.829 \\
\hline 4.9147 & 0.761 & 0.797 & 0.769 & 0.799 & 0.737 & 0.831 \\
\hline \multicolumn{7}{|c|}{$332.97 \mathrm{~K}$} \\
\hline 1.6415 & 0.000 & 0.000 & 0.000 & 0.000 & 0.000 & 0.000 \\
\hline 2.0331 & 0.073 & 0.174 & 0.074 & 0.182 & 0.072 & 0.178 \\
\hline 2.4133 & 0.145 & 0.300 & 0.144 & 0.303 & 0.143 & 0.307 \\
\hline 2.7202 & 0.202 & 0.377 & 0.200 & 0.378 & 0.199 & 0.385 \\
\hline 2.9828 & 0.249 & 0.430 & 0.247 & 0.430 & 0.245 & 0.441 \\
\hline 3.4126 & 0.326 & 0.500 & 0.323 & 0.498 & 0.320 & 0.514 \\
\hline 3.7826 & 0.390 & 0.545 & 0.388 & 0.545 & 0.381 & 0.564 \\
\hline 4.0316 & 0.432 & 0.570 & 0.432 & 0.570 & 0.422 & 0.593 \\
\hline 4.3599 & 0.488 & 0.597 & 0.491 & 0.598 & 0.474 & 0.625 \\
\hline 4.6754 & 0.545 & 0.611 & 0.551 & 0.615 & 0.523 & 0.652 \\
\hline 4.7138 & 0.553 & 0.611 & 0.559 & 0.616 & 0.529 & 0.655 \\
\hline \multicolumn{7}{|c|}{$348.40 \mathrm{~K}$} \\
\hline 2.2888 & 0.000 & 0.000 & 0.000 & 0.000 & 0.000 & 0.000 \\
\hline 2.5402 & 0.039 & 0.079 & 0.041 & 0.084 & 0.036 & 0.076 \\
\hline 2.681 & 0.066 & 0.128 & 0.064 & 0.124 & 0.059 & 0.120 \\
\hline 2.8847 & 0.095 & 0.170 & 0.096 & 0.175 & 0.092 & 0.177 \\
\hline 3.0338 & 0.120 & 0.209 & 0.120 & 0.208 & 0.116 & 0.213 \\
\hline 3.1956 & 0.145 & 0.239 & 0.145 & 0.241 & 0.142 & 0.249 \\
\hline 3.2858 & 0.158 & 0.256 & 0.159 & 0.257 & 0.156 & 0.268 \\
\hline 3.4679 & 0.189 & 0.288 & 0.187 & 0.287 & 0.184 & 0.303 \\
\hline 3.6675 & 0.218 & 0.316 & 0.219 & 0.315 & 0.215 & 0.337 \\
\hline 3.7671 & 0.237 & 0.331 & 0.234 & 0.328 & 0.231 & 0.352 \\
\hline 3.948 & 0.264 & 0.351 & 0.264 & 0.348 & 0.258 & 0.378 \\
\hline 4.0901 & 0.287 & 0.361 & 0.288 & 0.360 & 0.280 & 0.397 \\
\hline 4.2816 & 0.324 & 0.371 & 0.325 & 0.371 & 0.309 & 0.420 \\
\hline 4.3024 & 0.330 & 0.372 & 0.329 & 0.372 & 0.312 & 0.422 \\
\hline 4.3553 & 0.345 & 0.365 & 0.342 & 0.372 & 0.320 & 0.428 \\
\hline
\end{tabular}


Table 4: Values of the binary parameters at each temperature for the PR EoS using Mathias-Copeman alpha function and WS mixing rules involving NRTL model.

\begin{tabular}{ccccc}
\hline Data & $T / \mathrm{K}$ & $\tau_{12}$ & $\tau_{21}$ & $k_{12}$ \\
\hline 254.10 & 58 & -23 & 0.1078 \\
& 273.43 & 26 & -3 & 0.1204 \\
& 293.24 & -47 & 80 & 0.1637 \\
\hline 303.17 & -53 & 77 & 0.1961 \\
318.08 & 19 & -7 & 0.1820 \\
332.97 & 23 & -10 & 0.1841 \\
348.40 & 199 & -75 & 0.1870 \\
\hline
\end{tabular}


Table 5: Relative deviation AAD and BIAS obtained in fitting experimental VLE data with PR EoS using Mathias-Copeman alpha function and WS mixing rules involving NRTL model.

\begin{tabular}{cccccc}
\hline Data & $T / \mathrm{K}$ & Bias $x \%$ & AAD $x \%$ & Bias y $\%$ & AAD y \\
\hline 254.10 & 0.01 & 0.75 & -0.23 & 0.28 \\
273.43 & 0.15 & 0.20 & -0.39 & 0.40 \\
293.24 & -0.01 & 0.55 & -0.82 & 0.95 \\
\hline 303.17 & 0.77 & 1.16 & -0.45 & 0.55 \\
318.08 & 0.41 & 1.18 & -0.72 & 0.76 \\
332.97 & -0.06 & 0.75 & -0.75 & 0.79 \\
348.40 & -0.10 & 0.97 & -0.49 & 1.29 \\
\hline
\end{tabular}


Table 6: Pure compound PC-SAFT parameters regressed on VLE data.

\begin{tabular}{cccc}
\hline Compound & $\mathrm{m}$ & $\sigma(\AA)$ & $\varepsilon / \mathrm{k}(\mathrm{K})$ \\
\hline $\mathrm{R} 23$ & 2.6943 & 2.8280 & 148.187 \\
$\mathrm{R} 1234 \mathrm{yf}$ & 2.9872 & 3.3248 & 172.457 \\
\hline
\end{tabular}


Table 7: AAD and BIAS between the VLE data obtained by using REFPROP 9.0) and the PC-SAFT model, for the vapor pressures, and the saturated liquid and vapour densities of the two pure compounds R23 and R1234yf.

\begin{tabular}{ccccccc}
\hline Compound & $A A D P(\%)$ & $B I A S P(\%)$ & $A A D \rho_{L}(\%)$ & $B I A S \rho_{L}(\%)$ & $A A D \rho_{V}(\%)$ & $B I A S \rho_{V}(\%)$ \\
\hline R23 & 1.45 & -0.83 & 2.82 & 1.03 & 3.93 & 3.74 \\
R1234yf & 1.22 & -0.69 & 1.66 & 0.59 & 3.01 & 3.01 \\
\hline
\end{tabular}


Table 8. $\mathrm{k}_{12}$, AAD and BIAS calculated with PC-SAFT model for the R23 (1) - R1234yf (2) system .

\begin{tabular}{cccccc}
\hline $\mathbf{T} / \mathbf{K}$ & $\mathbf{k}_{\mathbf{1 2}}$ & $\mathbf{A A D} \mathbf{x}_{\mathbf{1}}(\boldsymbol{\%})$ & $\mathbf{B I A S} \mathbf{x}_{\mathbf{1}}(\boldsymbol{\%})$ & ${\text { AAD } \mathbf{y}_{\mathbf{1}}(\boldsymbol{\%})}$ & ${\text { BIAS } \mathbf{y}_{\mathbf{1}}(\boldsymbol{\%})}$ \\
\hline 254.10 & 0.0257 & 2.09 & 1.02 & 0.59 & -0.57 \\
273.43 & 0.0260 & 1.81 & 1.07 & 0.88 & -0.84 \\
293.24 & 0.0290 & 2.56 & 1.37 & 1.15 & -1.15 \\
303.17 & 0.0246 & 0.99 & 0.85 & 1.32 & -1.32 \\
318.08 & 0.0246 & 1.72 & 1.71 & 2.64 & -2.64 \\
332.97 & 0.0253 & 2.32 & 2.32 & 3.88 & -3.88 \\
348.40 & 0.0246 & 4.08 & 4.08 & 7.46 & -6.21 \\
\hline
\end{tabular}


Table 9: Extended scaling-law parameters $\lambda_{1}, \lambda_{2}$, and $\mu$ adjusted on experimental data.

\begin{tabular}{cccc}
\hline $\mathrm{T}(\mathrm{K})$ & $\lambda_{1 * 10^{4}}$ & $\lambda_{2 *} 10^{4}$ & $\mu * 10^{3}$ \\
\hline 303.17 & 859 & -1147 & 6.77 \\
318.08 & 839 & 1088 & 63.16 \\
332.97 & 826 & -1423 & 84.17 \\
348.40 & -509 & -1300 & 149.95 \\
\hline
\end{tabular}


Table 10: Critical point values determined by applying the scaling laws to the experimental data for the R23 (1) + R1234yf (2) binary system.

\begin{tabular}{ccc}
\hline$T / K$ & $P_{c}(M P a)$ & $x_{1 c}$ \\
\hline 303.17 & 4.90 & 0.96 \\
318.08 & 4.99 & 0.79 \\
332.97 & 4.87 & 0.60 \\
348.40 & 4.36 & 0.35 \\
\hline
\end{tabular}


Collected figures

Figure 1: VLE of the R23 (1) - R1234yf (2) system at different temperatures •: $254.10 \mathrm{~K}, \diamond: 273.43 \mathrm{~K}, \boldsymbol{\Delta}: 293.24 \mathrm{~K}, \mathrm{O}: 303.17 \mathrm{~K}, \diamond: 318.08 \mathrm{~K}, \Delta: 332.97 \mathrm{~K}$, $\square: 348.40$ K. ---: mixture critical point line.

Figure 2: Binary NRTL parameters $\tau_{12}(\Delta)$ and $\tau_{21}(\boldsymbol{\Delta})$ as a function of temperature. .... Vertical dotted line represents the R23 critical temperature.

Figure 3: $k_{12}$ binary parameter as a function of temperature using Peng Robinson EoS using Mathias-Copeman alpha function and WS mixing rules involving NRTL model.. .... Vertical dotted line represents the R23 critical temperature.

Figure 4: Vapor pressures of pure compounds R23 and R1234yf.

(O) REFPROP 9.0; (-) PC-SAFT.

Figure 5: P- $\rho$ diagram at saturation for R23 and R1234yf.

( ) REFPROP 9.0; (-) PC-SAFT.

Figure 6: Relative deviation (RD) for pure compounds R23 and R1234yf with PC-SAFT model.

( $\odot$ ) pressure; ( $\square$ )saturated liquid density; $(\Delta)$ saturated vapor density.

Figure 7: $k_{i j}$ as a function of temperature: R23-R1234yf with PC-SAFT model.

$(\boldsymbol{\Delta}) k_{i j} ;(---) \mathrm{R} 23$ critical temperature $\left(\mathrm{T}_{\mathrm{c}}=299.29 \mathrm{~K}\right)$

Figure 8. P-x-y diagram of the R23 (1) - R1234yf (2) system.

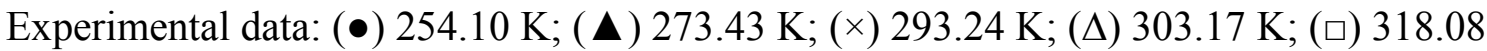
$\mathrm{K}$; ( $) 332.97 \mathrm{~K}$; (+) $348.40 \mathrm{~K}$. Modeling: (-) PC-SAFT

Figure 9: VLE of the R23 (1) - R1234yf (2) system at different temperatures. $\bigcirc: 303.17 \mathrm{~K}, \diamond: 318.08 \mathrm{~K}, \Delta: 332.97 \mathrm{~K}, \square: 348.40 \mathrm{~K}$. ---: mixture critical point line.

$\Delta$ : Mixture critical point calculated with the scaling laws (above the critical temperature of R23). 
Figure 1

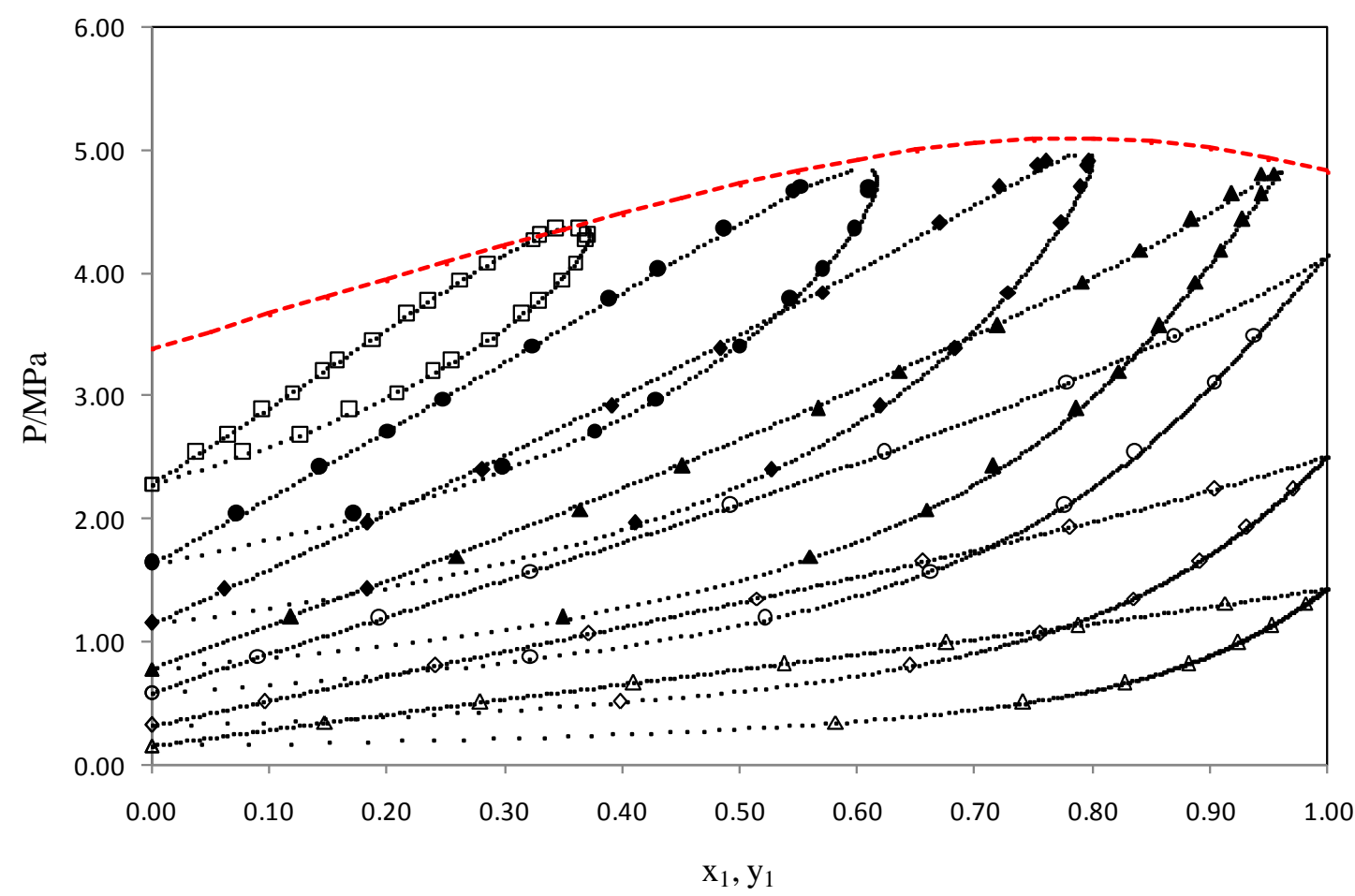


Figure 2

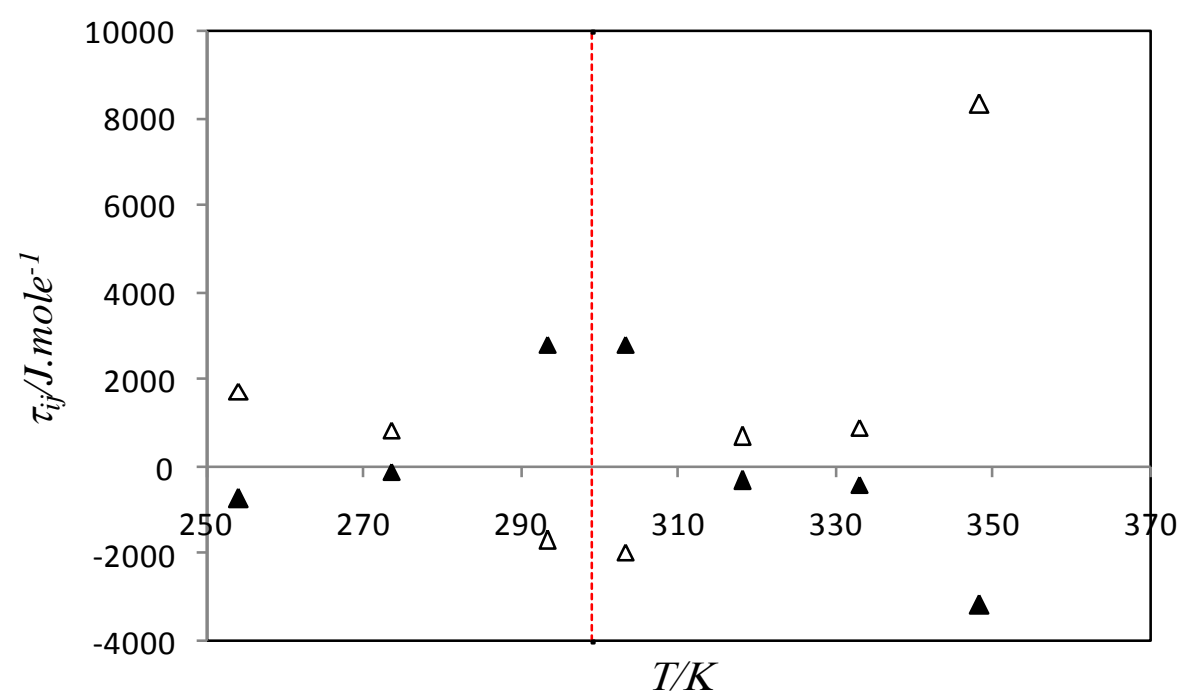


Figure 3

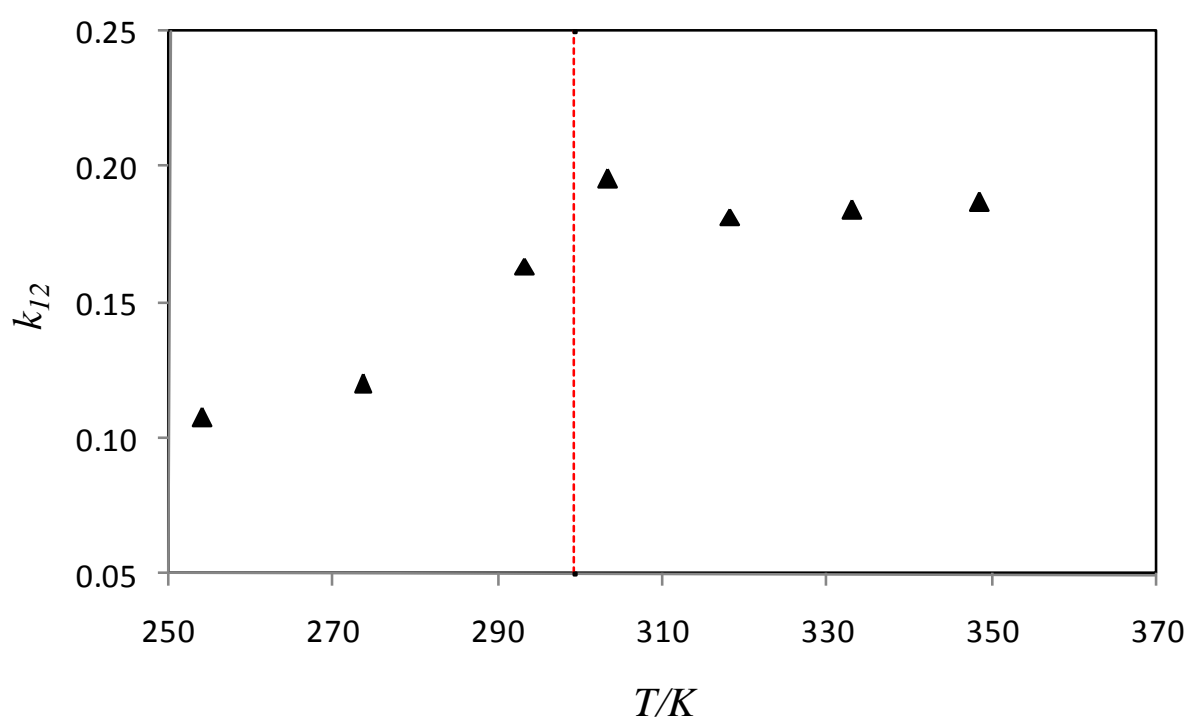


Figure 4

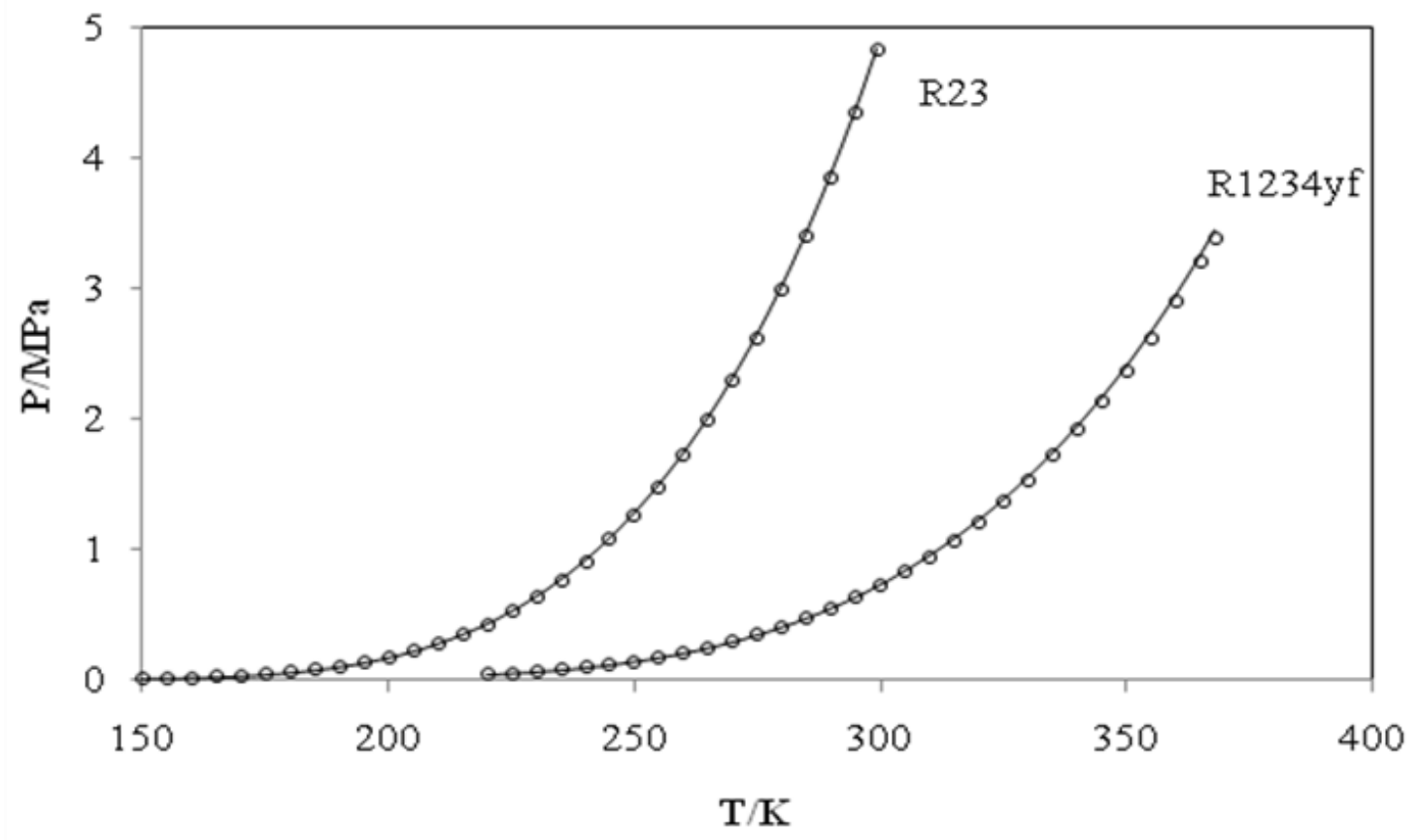


Figure 5
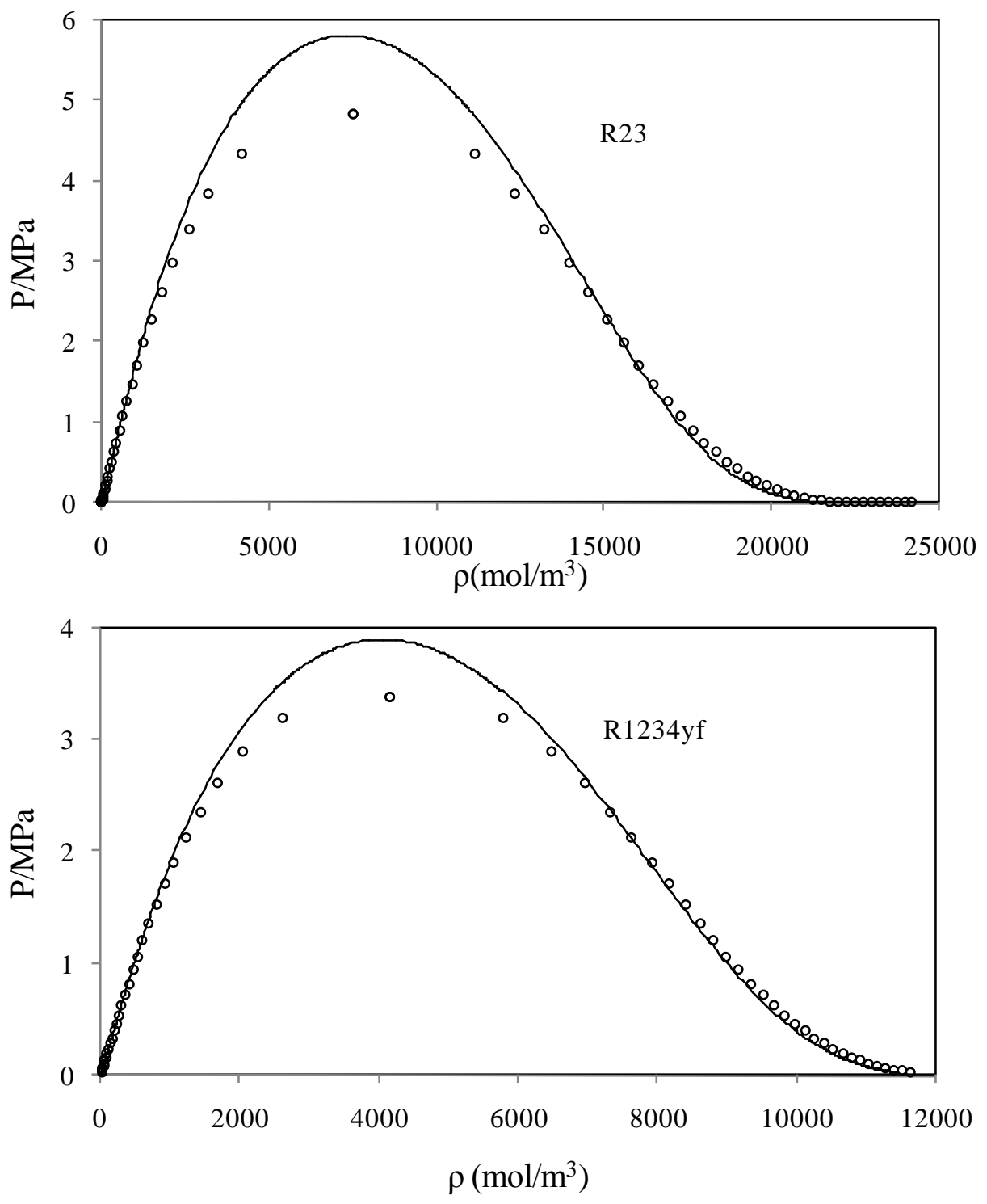
Figure 6
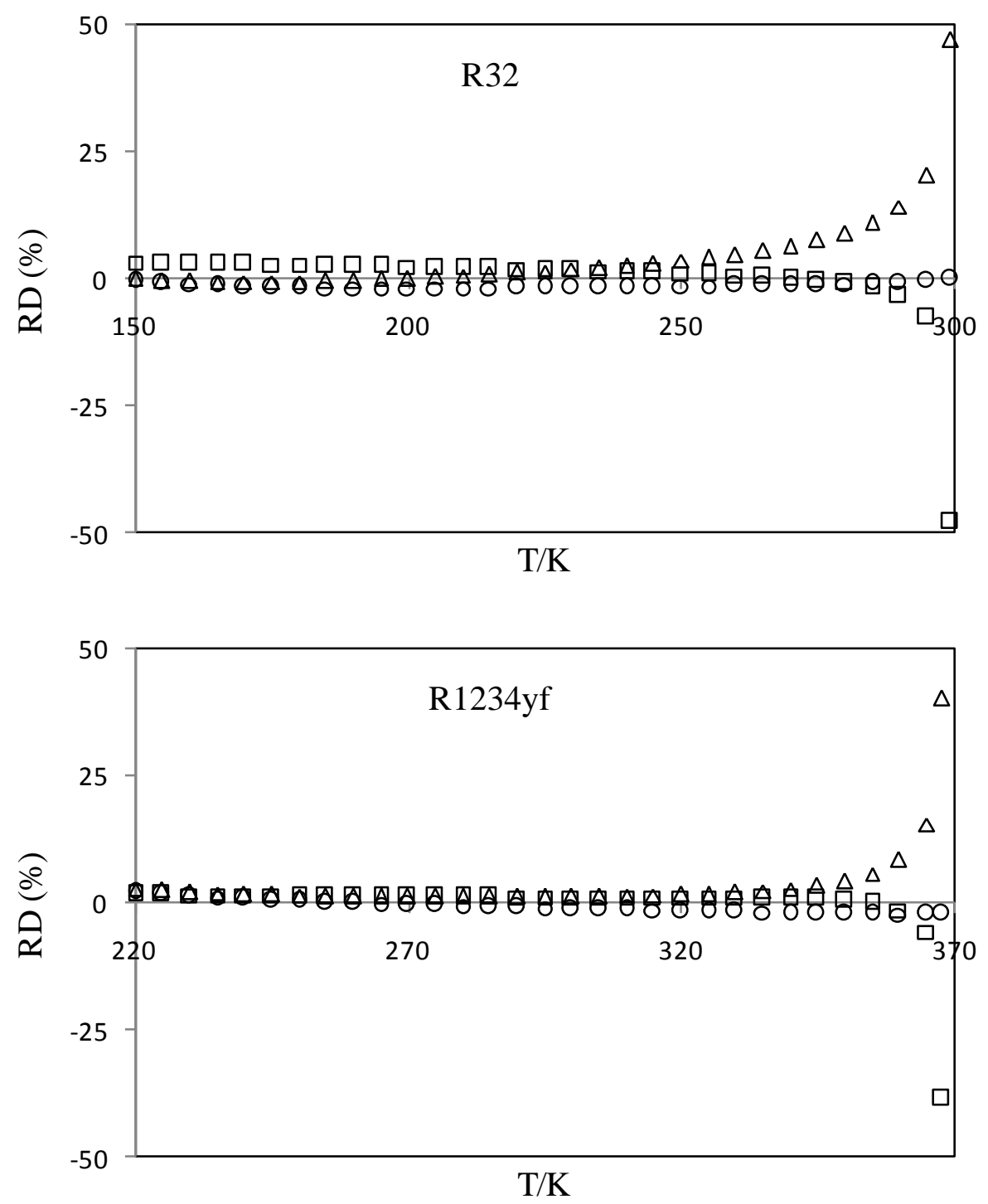
Figure 7

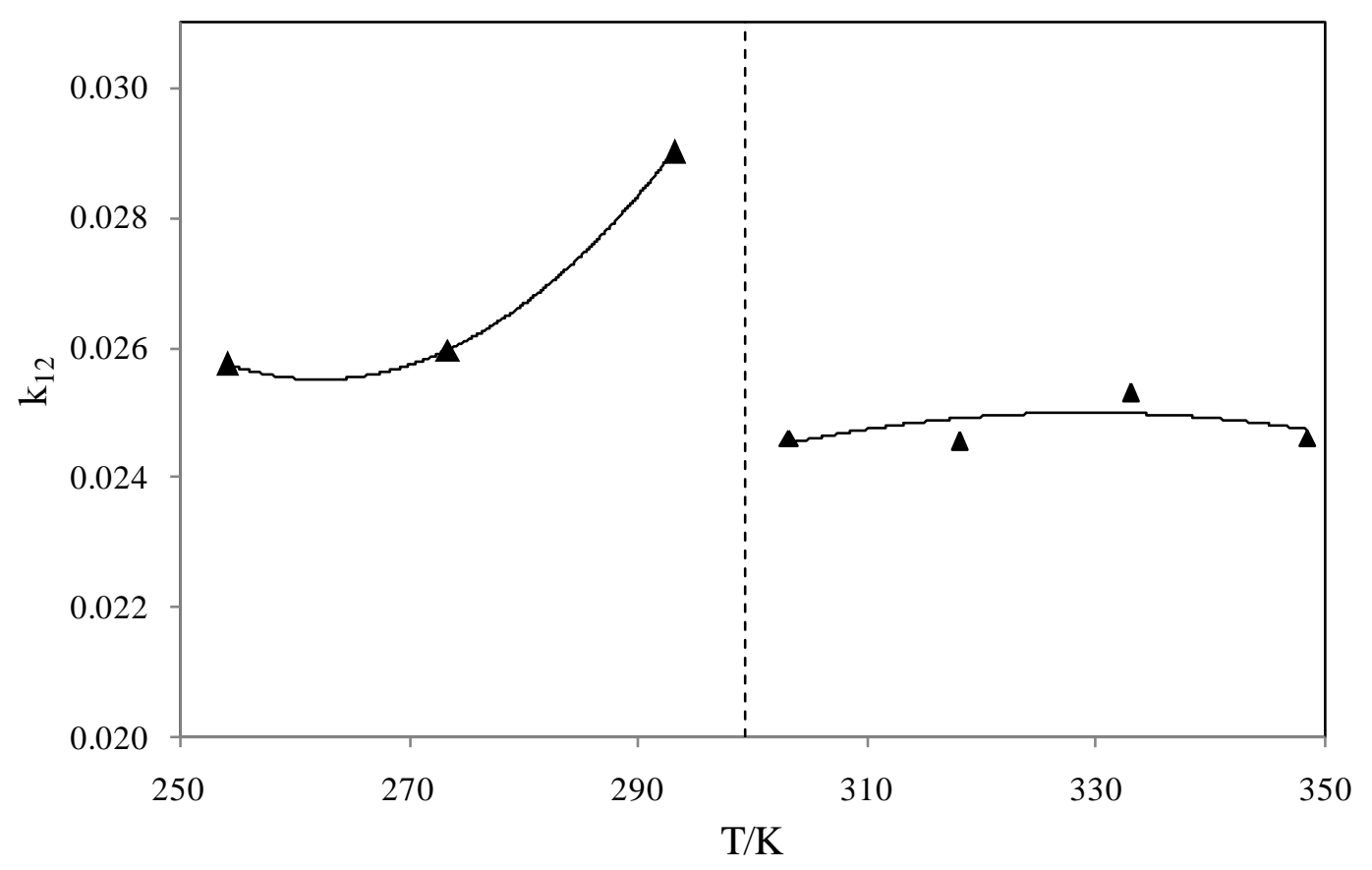


Figure 8

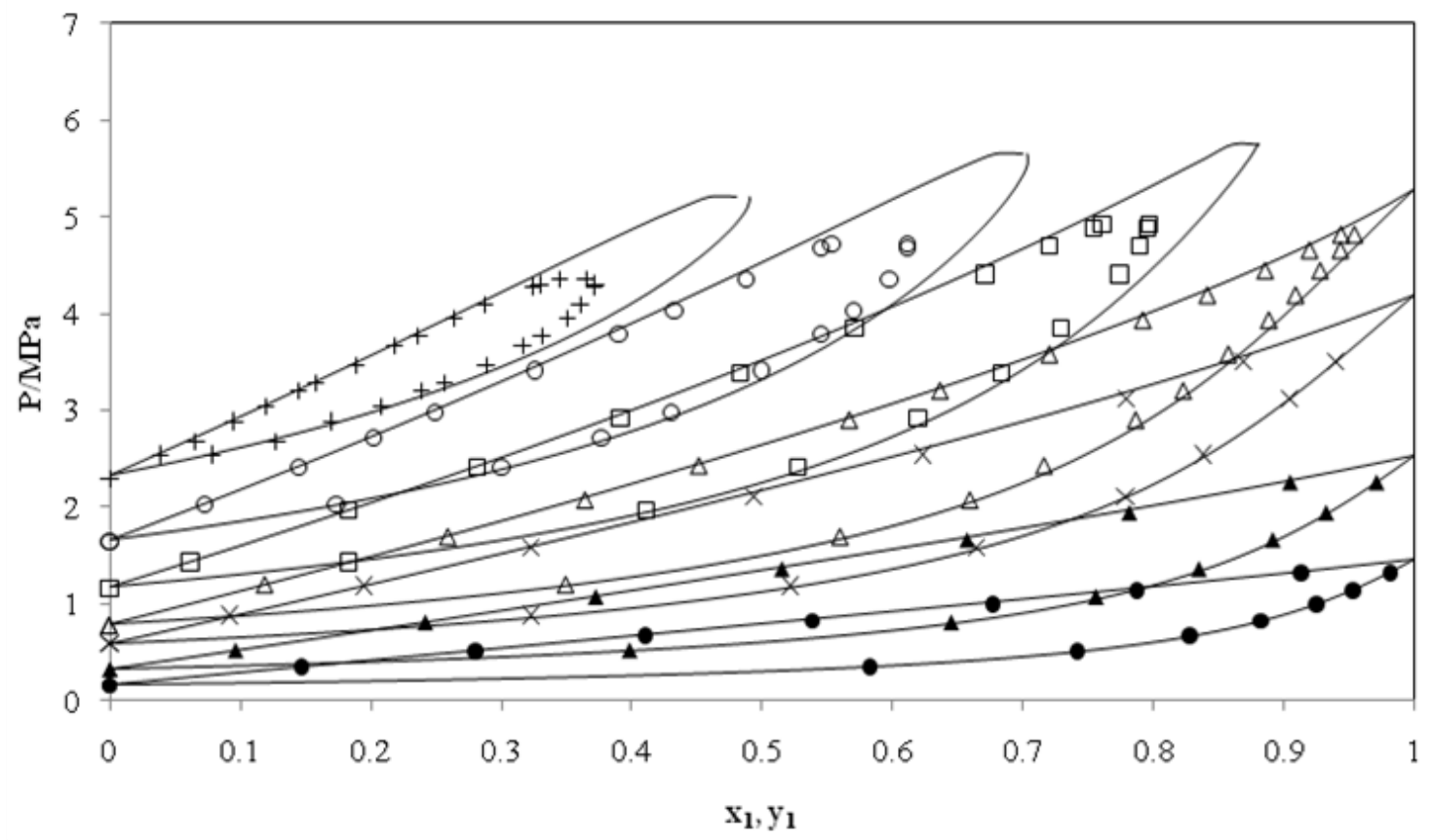


Figure 9

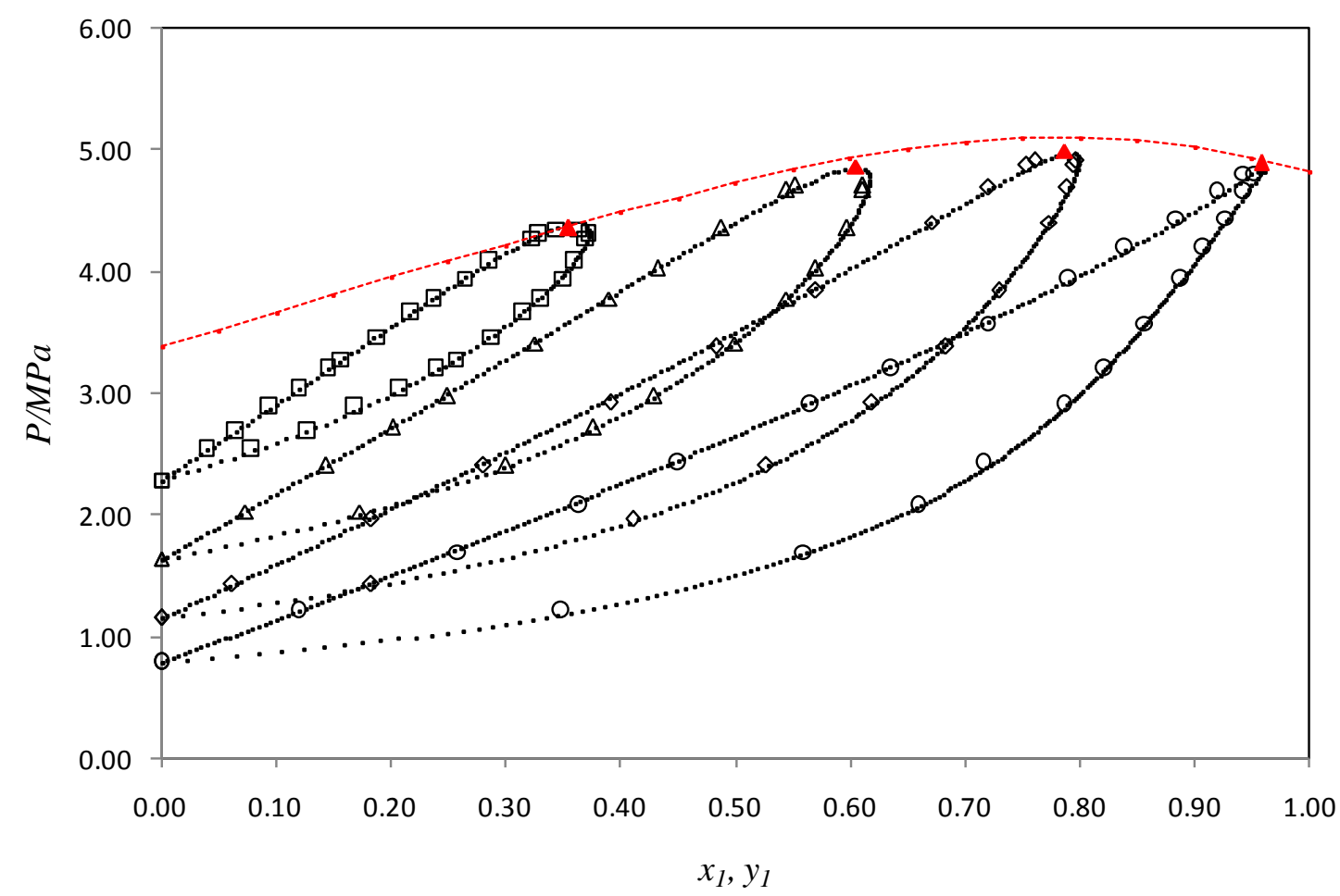

